
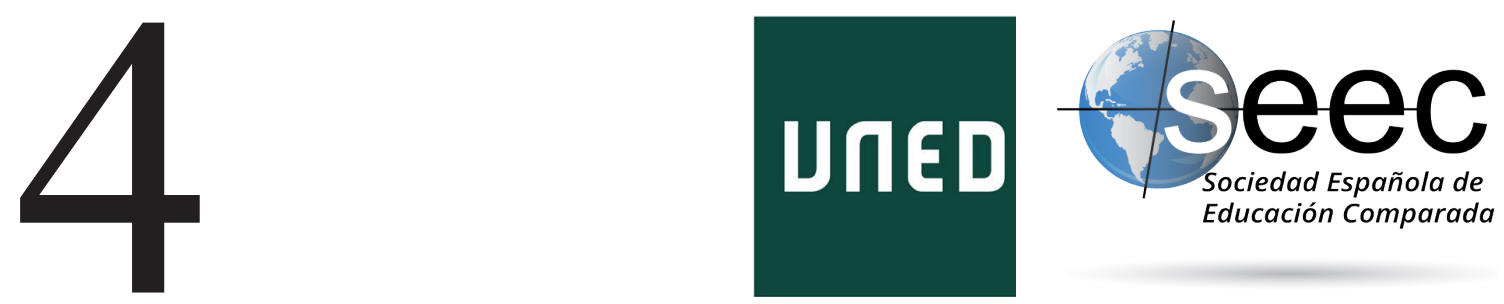

\title{
Educación comparada, Teología y Postrelativismo
}

Comparative Education, Theology and Post-relativism

\section{Ma José García Ruiz*}

DoI: $10.5944 /$ reec.33.2019.23148

\section{Recibido: 10 de diciembre de 2018 Aceptado: 24 de diciembre de 2018}

\footnotetext{
*María José García Ruzz: es Profesora Titular de Educación Comparada en la Universidad Nacional de Educación a Distancia (UNED). Pertenece a la Sociedad Española de Educación Comparada (SEEC), en cuya Junta Directiva sirve como Secretaria de la SEEC. Pertenece a la Comparative Education Society of Europe (CESE). Sus libros y artículos sobre la disciplina comparativa abordan en su mayoría temas vinculados con la epistemología y la metodología de esta disciplina.. Datos de contacto: E-mail: mjgarcia@edu.uned.es
} 


\title{
Resumen
}

Los procesos de Globalización y Postmodernismo han determinado la necesidad de operar un reajuste del corpus epistemológico de la disciplina comparativa de la educación necesario para integrar las exigencias gnoseológicas de dichos discursos en nuestro saber. Adicionalmente a ello, la resolución de las vulnerabilidades científicas de la Educación Comparada, y el logro de una fase postrelativista en la construcción del discurso de nuestra ciencia, requiere del concurso del trabajo interdisciplinar en la elaboración de dicho discurso. Particularmente imperioso se revela en el abordaje de los retos epistemológicos aludidos el acometimiento de un trabajo interdisciplinar con las ciencias teleológicas de la educación que cimienten y asienten en bases sólidas la elaboración y articulación de una disciplina comparativa fecunda y estable, más allá de los cambios teóricos disciplinares que conllevan los ciclos históricos sucesivos.

Palabras clave: Globalización; Postmodernidad; Educación Comparada; epistemología; interdisciplinariedad; Teología

\begin{abstract}
The phenomena of Globalization and Postmodernism have determined the need to overtake a readjustment of the epistemological corpus of the comparative discipline in Education, necessary to integrate the demands of such discourses in our academic field. Additionally, the resolution of the scientific vulnerabilities of Comparative Education, and the achievement of a postrelativistic phase in the construction of the discourse of our discipline, demand the competition of an interdisciplinary work in the construction of such discourse. Particularly overriding in the approach of the epistemological challenges mentioned, is the commitment of an interdisciplinary work with teleological sciences of education, that allow the foundation and settlement in solid basis of a fertile and stable comparative discipline, beyond the natural changes of successive historical cycles.
\end{abstract}

Key Words: Globalization; Postmodernity; Comparative Education; Epistemology; Interdisciplinarity; Theology 


\section{Vulnerabilidad y fortaleza de la Educación Comparada}

El carácter internacional y transfronterizo del proceso de la Globalización conduce inexorablemente a la potenciación y legitimación de disciplinas como la Educación Comparada. En este sentido, autores como Cowen y Kazamias prodigan la gran fecundidad de esta disciplina en estos primeros años del siglo XXI en términos de producción científica y organización de congresos y redes internacionales (Cowen \& Kazamias, 2009, pp. 3-4). No obstante, estos autores matizan y apuntalan su diagnóstico introduciendo un cierto escepticismo en sus manifestaciones en relación a la salud real de nuestra disciplina: "Las estructuras superficiales de la Educación Comparada -sus revistas, sus departamentos, sus sociedades profesionales- parecen gozar de una excelente salud. Por debajo de la superficie, no obstante, hay confusiones en relación a lo que de hecho es la Educación Comparada o lo que ella podría ser» (Cowen, 2009, p. 964).

Los académicos comparatistas de la educación nos hallamos en un momento de reajuste del corpus epistemológico y metodológico de la disciplina necesario para integrar las exigencias gnoseológicas de los discursos postmodernos en nuestro saber. Con vistas a que este proceso sea operado con las máximas garantías de fecundidad y éxito, la comunidad comparatista de la educación debemos acometerlo desde el reconocimiento de los puntos vulnerables de nuestra ciencia, y de los elementos -también- de extraordinaria fortaleza que permiten la vertebración de nuestra disciplina en sólidas bases futuras.

Las dificultades epistemológicas de la Educación Comparada son reconocidas por la gran mayoría de académicos comparatistas de los diversos entornos geográficos. Así, Rappleye (2014, p. 93) afirma que «(...) la disciplina está (...) de forma incesante en búsqueda de sí misma». Por su parte, Manzón (2014, p. 127) se pregunta: «¿jpor qué no hay una forma universal de Educación Comparada?». La pluralidad (algo caótica, podemos decir) del ámbito de la Educación Comparada ha sido resumida por académicos como Cowen en la afirmación de que «existen muchas educaciones comparadas» (2009, p. 4). En su emblemática obra de Fundamentos de la epistemología de la Educación Comparada, el catedrático español García Garrido también se hace eco de las «discusiones y muchos más desacuerdos sobre su objeto» (1996, p. 113) que tradicionalmente han caracterizado a la epistemología de esta ciencia. García Garrido enumera hasta seis posturas existentes defendidas por los diversos académicos comparatistas en relación con el objeto científico de la Educación Comparada (1996, pp. 92-96). Así, si bien la disciplina de la Educación Comparada se revela un ámbito científico de gran tradición y solera que se remonta a la Antigüedad Grecorromana, en estos primeros años del siglo XXI esta ciencia sigue revelando una extraordinaria pluralidad, heterogeneidad, hibridación, diversidad y eclecticismo que han determinado la gran dificultad experimentada por los académicos consagrados a la misma en articular de manera consensuada elementos epistemológicos básicos como, muy particularmente, el objeto de estudio de la misma. Podemos afirmar sin ningún género de dudas, que esta heterodoxia y disenso En relación con el elemento más nuclear y sensible de un campo científico -su objeto de estudio- constituye una de las mayores vulnerabilidades, quizá la mayor, que aquejan al desarrollo unánime y coordinado del corpus epistemológico comparativo en educación. Como todos los comparatistas de la educación conocen, durante largo tiempo en el desarrollo de la disciplina durante la Modernidad, un número mayoritario de académicos comparatistas, tanto en 
el siglo XIX como en el siglo XX (en no escasa medida por decisivo influjo del precursor positivista Jullien de Paris), se han suscrito en sus trabajos académicos a la concepción del objeto de estudio de la Educación Comparada como el estudio comparado de los «sistemas educativos». Acreditados comparatistas han luchado a favor de una interpretación amplia de esa concepción objetual, advirtiendo de la necesidad de «eliminar la actual identificación fáctica entre lo educativo y lo escolar" (García Garrido, 1996, p. 110). Con esta apostilla estos académicos no solo han roto una lanza en favor de las concepciones y el carácter educativo de los entornos no formales sino que, al mismo tiempo, y sin explícitamente pretenderlo, han avanzado hacia posturas epistemológicas cercanas a las sostenidas por científicos como Tusquets, los cuales abogan por una concepción de la Educación Comparada como ciencia o saber que se articula en torno al estudio comparado de la «educación» ampliamente entendida a través del método comparado, aspecto este último cuyo rigor y fundamento cobran una importancia mayúscula como sustento de primer orden de la investigación comparativa. El comparatista británico Cowen, en su extraordinaria e innovadora obra International Handbook of Comparative Education, IHCE, editada de forma conjunta con el comparatista griego-americano Kazamias, también aborda la temática objetual. Su visión ontológica es interesante, y está a caballo entre la concepción objetual de Tusquets y la de los académicos más ortodoxos. Así, Cowen esboza que, más allá de la variación de los «puzzles normales» de un determinado periodo (Cowen, 2009, p. 1.285), hay ciertos temas básicos que todos los académicos de la Educación Comparada han explorado a lo largo de un prolongado período de tiempo: "hay una sorprendentemente similar agenda profunda» (ídem). Dicha agenda, en su análisis, se vertebra en torno y en el seno de una constelación de ideas nucleares o «ideas unitarias» que, prácticamente, unifican este campo de estudio. La entidad de dichas ideas es la siguiente: espacio, tiempo, el Estado, sistema educativo, identidad educada, contexto social, transferencia y praxis (ídem). En el apartado prospectivo que Cowen redacta en esta emblemática obra del IHCE, este académico añade las ideas de «cambio de forma»-shape shifting-, «rosetas educativas», vuelta a la tríada de relaciones (transferencia, traslación y transformación), y lectura de lo global, como ideas de necesario procesamiento y abordaje en la construcción epistemológica del ámbito comparado en educación para superar la «trampa modernista» y el subsiguiente dilema de un bajo nivel de problemática intelectual y teórica, en la construcción de la epistemología comparativa (Cowen, 2009, p. 1.288).

Un segundo elemento de vulnerabilidad en nuestro ámbito disciplinar lo constituye la cuestión metodológica. Hace unas décadas, el desarrollo de la disciplina comparativa de la educación en líneas de Modernidad reveló un cierto consenso metodológico en torno al cual se articuló el trabajo de los comparatistas: «(...) el acuerdo sobre la existencia y aplicabilidad a la educación del método comparativo ha sido una constante -iuna de las pocas! - entre los cultivadores de nuestra disciplina, de Jullien a nuestros días» (García Garrido, 1996, p. 114). No obstante, este mismo experto comparatista admite, tras ello, la existencia de enfoques diversos en la metodología comparada (ie. descripción, explicación, aplicación, valoración) y, a la postre, la «validez científica de una pluralidad de enfoques metodológicos» y la necesidad de «evitar la tentación del monopolio metodológico» (ibídem, pp. 115-121); además de reconocer la existencia de métodos y técnicas auxiliares que incluyen la contribución de la reflexión filosófica, de la metodología histórica y de las aportaciones de las ciencias sociales (ibídem, pp. 136-166). 
El aspecto metodológico de las investigaciones comparativas constituye una de las partes más sensibles y relevantes de los estudios de nuestro ámbito. El editorial del mes de noviembre de 2017 de la norteamericana Comparative Education Review, CER, reivindica el «rigor y solidez metodológicas de los manuscritos» que se envíen a esta revista, tanto si los estudios comparativos se vertebran en líneas cuantitativas como cualitativas. El equipo editorial de la $C E R$ comunica que, en lo que atañe al plano metodológico, las decisiones editoriales se adoptan en base a la «fortaleza de este análisis» (Editorial, $C E R$, noviembre 2017, vol. 61, número 4). Uno de los académicos que más ha contribuido al replanteamiento de la cuestión metodológica de la Educación Comparada es el comparatista germano Jürgen Schriewer. Sus planteamientos metodológicos apuntan a «relativizar las metodologías ortodoxas» (Schriewer, 200o, p. vii) y a reivindicar la «crisis del universalismo», la complejidad y la impredecibilidad. La cuestión metodológica sigue abierta, y su articulación y forma concretas se revelan en dependencia directa de las contribuciones, y de la misma metodología, de las ciencias sociales que coadyuvan en cada caso en la elaboración de los análisis comparativos. Especial mención merece, por sus relevantes aportaciones al plano metodológico del análisis comparativo, la obra del catedrático comparatista de la Universidad de Alicante (procedente del ámbito de la Literatura comparada), el Dr. Pedro Aullón de Haro. Este académico dirige el Instituto Juan Andrés de Comparatística y Globalización. Como curiosidad comparatista, el Dr. Aullón de Haro reivindica la figura del alicantino Juan Andrés (1740-1817) como primer comparatista español, pionero y anterior al emblemático Jullien de Paris. En su obra Metodologías comparatistas y Literatura comparada (2012), este autor revela su concepción epistemológica en líneas cercanas a los pedagogos García Hoz, Villalpando o Nassif, afirmando que la comparación es un método y el comparatismo o la comparatística una gama metodológica, no una ciencia o una gama de disciplinas autónomas. Su obra escrita y su recién inaugurada revista Metodologías humanistas en la era digital constituyen un valioso referente para el campo abierto y de variado diseño y complejidad de la metodología comparada o, más exactamente, las metodologías comparatistas.

En la solventación de las vulnerabilidades de nuestra disciplina, el trabajo interdisciplinar no solo se revela imperativo y crucial, sino que constituye una de las principales fortalezas de los estudios comparados acreditados. Cowen revela el hecho de que la revitalización intelectual de la Educación Comparada se ha producido «desde fuera» de la disciplina y, muy especialmente, procede del ámbito de la Sociología y la Historia (Cowen, 2009, pp. 1.279-1.280). Este académico apunta al ascenso del trabajo teórico comparativo problematizado gracias a las aportaciones del marxismo y sus variaciones, además de a los escritos En relación con el colonialismo y al análisis de los sistemas mundiales. El Catedrático Emérito García Garrido también alude en su obra al hecho de que «la Educación Comparada es un ámbito sustancialmente interdisciplinario» (1996, p. 138), esbozando que «es deseable que el comparatista tenga una buena formación previa en al menos un campo de especialización (Historia, Ciencia Política, Sociología, Economía, etc.), además de en Pedagogía (1996, p. 139). La interdisciplinariedad constituye, pues, la principal fortaleza de nuestra disciplina, y solo si en la construcción epistemológica de la misma contamos con los aportes gnoseológicos y metodológicos de otras ciencias, la Educación Comparada podrá fortalecerse y salir robustecida de los embistes globalizadores y postmodernos con los que se enfrenta en estos años del siglo XXI. Adicionalmente, por su carácter de ciencia de rango analítico sintético, la Educación Comparada no debe solo relacionarse con las ciencias analíticas de índole antropológica y metodológica de la 
educación -que son con las que tradicionalmente ha tenido más relación (ie. Sociología, Política) - sino también muy especialmente con las analítico sintéticas (ie. Historia), las sintéticas (ie. Pedagogía General) y, en estos complejos años de comienzos del siglo XXI, muy primordialmente con las disciplinas teleológicas (ie. Filosofía y Teología). En este tiempo de globalización y modernidad tardía, la Educación Comparada solo logrará cimentar y estabilizar su objeto de estudio, y solo se verá capacitada para dar cumplida y eficaz respuesta a sus finalidades teóricas y aplicadas si desarrolla su epistemología de forma conjunta muy especialmente con las ciencias teleológicas. Retomaremos esta reflexión en líneas posteriores.

\section{Modernidad, Postmodernidad y Postrelativismo}

Precisamente, la grave y prolongada carencia de un trabajo interdisciplinar en Educación Comparada es la responsable de la «ausencia de rol de la comunidad de comparatistas de la educación en la discusión postmoderna» (Rust, 1991, p. 614). Según el comparatista Val D. Rust, «la idea postmoderna ha existido en la ciencia social y la literatura estética desde la década de 1950 (ibídem, p. 610). El historiador Perry Anderson, de la Universidad de California (UCLA), en su obra Los orígenes de la posmodernidad, remonta más atrás en el tiempo el origen de este fenómeno. Así, Anderson afirma que la idea de postmodernismo emergió primero en el intermundo hispano en los años treinta del siglo XX, una generación antes de su aparición en Inglaterra y los EE.UU. (Anderson, 2000, p. 8). La aparición de este término en el mundo anglófono no se produjo sino hasta veinte años más tarde, en un contexto muy distinto y como categoría histórica más que estética (ibídem, p. 9). El célebre historiador Toynbee introduce el término de «edad postmoderna» en el octavo volumen de su colección publicado en 1954. A su parecer, la edad moderna estaba marcada por dos procesos: el auge de una clase obrera industrial, en Occidente y, en el resto del mundo, el esfuerzo de las sucesivas intelligentsias por dominar los secretos de la modernidad y volverlos contra Occidente. Sus ejemplos eran el Japón de la era Meiji; la Rusia bolchevique; la Turquía kemalista y la recién nacida China maoísta (ibídem, p. 10).

La Postmodernidad, también denominada posthumanismo, posthistoricismo (Kunitz, 1955) o Post-Occidente (Olson, 1987), no alcanzó difusión más amplia hasta los años setenta. La apropiación de la insignia postmoderna de los arquitectos, que se produjo entre 1977 y 1978, resultó duradera. La primera obra filosófica que adoptó la noción fue La condition postmoderne de Jean-François Lyotard, publicada en 1979 en Paris. Para Lyotard, la llegada de la postmodernidad estaba vinculada al surgimiento de una sociedad postindustrial, teorizada por Daniel Bell y Alain Touraine, en la que el conocimiento se había convertido en la principal fuerza económica de producción; en un flujo que sobrepasaba a los Estados nacionales, y al mismo tiempo había perdido sus legitimaciones tradicionales. Según Anderson, el rasgo definitorio de la condición postmoderna (2000, p. 31-32) es la pérdida de credibilidad de las metanarrativas modernas. Entre estas destacan las metanarrativas derivadas de la Revolución Francesa, y las que descendían del idealismo alemán. A ellas Lyotard amplió y declaró difuntas a la redención cristiana, el progreso de la Ilustración, el espíritu hegeliano, la unidad romántica, el racismo nazi y el equilibrio keynesiano. Frente a ello emergió la proliferación de la paradoja, del paralogismo, los descubrimientos del caos y la «teorización de la propia evolución como discontinua, catastrófica, no rectificable y paradójica» (ídem). Al parecer 
de Anderson, la narrativa como tal no desaparece en los tiempos postmodernos, sino que se vuelve miniaturizada y competitiva. Su equivalente social es la tendencia al contrato temporal en todos los ámbitos de la existencia humana, el ocupacional, el emocional, el sexual y el político: unos lazos más económicos, flexibles y creativos que los vínculos de la modernidad (ídem).

Las reflexiones del filósofo Habermas en su discurso de 1980 titulado La modernidad, un proyecto inacabado, ocupan un lugar a la par peculiar y privilegiado dentro del discurso de la postmodernidad. Las aserciones de Habermas constituyen las primeras en las que la idea de la postmodernidad recibió un tratamiento negativo. El proyecto ilustrado de la modernidad tenía dos vertientes. Por un lado, la ciencia, la moralidad y el arte, al no estar ya fundidos en una religión revelada, se diferencian por primera vez en unas esferas de valor autónomas, gobernadas cada una por sus propias normas: verdad, justicia y belleza. Por el otro lado, se trataba de verter el potencial de esos dominios recién liberados al flujo subjetivo de la vida cotidiana, en el cual pudieran interactuar para enriquecerlo. Según Habermas (Anderson, 2000, pp. 42-51) este era el proyecto de la modernidad aún por realizar: la reapropiación de las culturas de expertos que cada uno de esos dominios había producido y su integración en el lenguaje de la experiencia común. Según Ánderson,el «proyecto» de la modernidad, tal como lo describe Habermas, es una amalgama contradictoria de dos principios opuestos: la especialización y la popularización. Las intervenciones de Lyotard y Habermas, al parecer de Anderson, sellaron el terreno por primera vez con el cuño de la autoridad filosófica.

En el ámbito de la Educación Comparada, uno de los primeros trabajos comparatistas que integran el postmodernismo en la epistemología de esta disciplina fue el de Val D. Rust, en el año 1991, con su artículo Postmodernism and Its Comparative Education Implications, publicado en la norteamericana Comparative Education Review. La tardía entrada de la comunidad de comparatistas de la educación en la discusión postmoderna se debió, según Rust, a dos factores. El primero radica en el hecho de que gran parte de nuestro campo apunta al mundo en desarrollo, mientras que el postmodernismo se focaliza casi exclusivamente en Europa y Norteamérica. El segundo estriba en que la comunidad educativa profesional más amplia solo recientemente ha participado en las discusiones postmodernas (Rust, 1991, p. 614). Así pues, hasta fechas recientes, el principal marco teórico que informó la investigación en Educación Comparada ha sido el de la modernización.

Rust señala cuatro problemas cruciales para nuestro campo comparativo derivados de la dimensión postmoderna, de los cuales vamos a referirnos a dos: la naturaleza totalitaria de las metanarrativas, y los problemas del Otro. En lo que atañe al primer problema, el postmodernismo revela una gran «incredulidad hacia las metanarrativas» (ibídem, p. 615), las cuales «encierran a la civilización en sistemas de pensamiento totalitarios y logocéntricos», como la «visión modernista de que el conocimiento y la verdad se basan en principios abstractos y constructos teóricos más que en experiencia humana directa y subjetiva» (ídem). Según Foucault, estas teorías globales o totalitarias son vulnerables a los «criticismos o críticas locales» y productos teóricos «no centralizados». Según Rust, «un desafío del postmodernismo a los comparatistas de la educación es la clarificación de las metanarrativas que presiden nuestro trabajo y que tendemos a universalizar» (ibídem, p. 616). A su parecer, las metanarrativas legítimas deberán abrir el mundo a sociedades e individuos, a través de la provisión de formas de análisis que expresen y articulen diferencias y que promuevan el pensamiento crítico sin cerrar el pensamiento y las vías 
para la acción constructiva. Los postmodernistas rechazarían cualquier pretensión de que una manera de conocimiento es la única vía legítima (ídem).

En lo que atañe al segundo aspecto, el problema con el Otro, el replanteamiento de esta temática censura el Eurocentrismo (y su sentido de superioridad atribuido a movimientos como el proyecto de la Ilustración) y el Imperialismo. El nuevo tiempo postmoderno, en el que con creciente fuerza y presencia se hacen sentir movimientos de liberación y autodeterminación que involucran grupos étnicos, minorías, grupos de vida alternativa, representantes de gays y lesbianas, feministas, etc., demanda una nueva y plena participación en la toma de decisiones en todo tipo de vida social y política, incluida la escuela, el ámbito laboral y el gobierno local. Según Rust, «el símbolo más obvio de la nueva era es la obsolescencia de la norma de la mayoría, la cual mitiga la variedad, la apertura y la diversidad» (Rust, 1991, p. 618). Está en juego la misma identidad de las culturas tal y como las hemos conocido en la modernidad (ídem).

Podemos afirmar que, si la modernidad se vincula a ideas de tradición continuada, Cristianismo, Europa, racionalismo, universalismo, normativismo, tradición, moralidad, historia y virtudes, la postmodernidad se asocia a ideas de ruptura, cultura de lo nuevo, movilidad, aceleración de la historia, discontinuidad, nuevo valor atribuido a lo transitorio, lo esquivo y lo efímero (Habermas, 1988, p. 89), rebelión contra todo lo que es normativo, contra la tradición, posthistoricismo (García Ruiz, 2011) y, muy especialmente, a un parámetro muy característico de la epistemología postmoderna, que constituye uno de los rasgos más presentes y generalizados en la cultura de la modernidad tardía, que ha sido muy contestado por la gran mayoría de los académicos, y cuyo análisis detenido debemos necesariamente acometer para dar respuesta a las inquietudes epistemológicas que suscita en la construcción de conocimiento científico y comparativo. Este parámetro es el relativismo.

El rasgo del relativismo es un atributo universalmente reconocido como signo y símbolo del estado epistemológico de la postmodernidad. Anderson (2000, p. 33) afirma que el relativismo «pasa por ser la marca distintiva de la postmodernidad». El profesor Cowen, en sus escritos en el International Handbook of Comparative Education de 2009 alude al «problema relativista» y se pregunta, como interrogante e inquietud epistemológica primordial actual: «¿dónde están los límites del relativismo?». Académicos y teólogos como el Papa Emérito Benedicto XVI se refieren a la «Dictadura del relativismo» como signo del estado epistemológico característico de estos años del siglo XXI (Sayés, 2012, p. 9).

Desde un prisma histórico y filosófico, podemos afirmar la existencia omnipresente de relativistas a lo largo del tiempo, desde los sofistas de la antigua Grecia. La raíz del relativismo ético de nuestros días, en Occidente, la encontramos en la filosofía de Guillermo de Ockham. La filosofía de Ockham sentó las bases del relativismo ético. Y ella, según Poole Derquí, sirvió al pensamiento posterior tanto para fundar la realidad moral solo en la voluntad de Dios (ie. los protestantes, empezando por Lutero), o solo en la naturaleza humana (ie. los racionalistas modernos). Los reformadores protestantes marginaron el estudio de la ley natural, y de la razón natural que la conoce; y los secularistas modernos, centrados solo en la razón humana, prescindieron de la ley divina, y de la fe por la que llegamos a conocerla. De este modo, la razón y la fe llegaron a ser enemigos en lugar de los aliados que fueron durante toda la filosofía clásica medieval (2016, p. 16). Por contraste, la filosofía medieval anterior a Ockham consideraba buena la acción humana tanto por su conformidad con la naturaleza humana como por su adecuación a la voluntad divina (ídem). 
Tras Ockham, el racionalismo secularista de la Ilustración prescindió del orden de la creación impuesto por Dios para justificar toda la moralidad desde el pensamiento del hombre. El empirismo que siguió a esa corriente filosófica reemplazó la lógica racionalista de las ideas inmutables del entendimiento humano, por las sensaciones. Hume desarrolló la teoría emotivista del valor y, a partir de ahí, la moral es siempre una proyección subjetiva y relativa al sujeto que produce el juicio moral, y la moral se entiende como sentimiento en lugar de conocimiento (ibídem, p. 7). La concepción relativista de la moral fue promovida por la moral kantiana, por el idealismo hegeliano, y por otros grandes filósofos del siglo XX como Kelsen, Weber y Berlín.

El fenómeno del relativismo consiste y surge a partir de la crisis y negación de las metanarrativas universales. Desde el prisma de la construcción del conocimiento científico, hablamos de relativismo epistemológico. En los argumentos de los comparatistas de la educación que han abordado «el problema relativista» (Cowen, 2009, p. 961), como el británico Cowen, es, no obstante, el relativismo ético el que con mayor presencia y fuerza inquieta e impacta en los actuales planteamientos epistemológicos (frente a otros tipos de relativismo como el cultural, el individual o el sociológico). La inquietud de Cowen más objetivamente explicitada radica en el conocimiento de la entidad e identidad del momento concreto y de los criterios específicos que deben presidir la emisión de juicios (mayormente ausentes en los escritos de los comparatistas, afirma él) «condenadores de modelos educativos (...) como la presión extrema impuesta a los alumnos por los sistemas de exámenes en Japón, Hong Kong o Corea del Sur» (ibídem, p. 962). Cowen aduce que los comparatistas de la educación, por su misma inmersión en esta disciplina específica, "han aprendido a amar lo exótico y lo extraño», siendo fomentadas como virtudes profesionales adquiridas la tolerancia y la empatía con lo extraño (ídem), aunque dichos entornos revelen prácticas pedagógicas y educativas censurables y reprobables, las cuales quedan sin cuestionar.

No todos los académicos actuales comulgan con el relativismo reinante. El relativismo es, de hecho, «el rasgo de la Postmodernidad más enérgicamente rechazado por un gran número de académicos» (García Ruiz, 2012, p. 48). Tampoco todos los académicos admiten la relegación y el rechazo en estos tiempos de modernidad tardía de atributos característicos de la Modernidad de gran valía como, muy especialmente, la tradición y la verdad. En su obra Relativismo y tolerancia, Poole Derquí avanza la crítica de que «todo relativismo que pretenda ser razonado implica una contradicción consigo mismo: si ningún criterio puede ser verdadero, el juicio de que toda verdad es relativa tampoco puede tener carácter de validez absoluta, lo que destruye, con sus propias armas, al relativismo» (2016, pp. 8-9). Poole también combate con lucidez la negación de las promesas liberales de progreso y mejora por la Postmodernidad: «(...) un fin es valioso, no porque se desea, sino porque objetivamente el hombre se hace mejor al conseguirlo. Lo cual presupone una idea de «progreso» en la vida humana. En el plano físico e intelectual nadie discute que el hombre está en un continuo proceso de desarrollo, pero en el moral muchos dudan de que haya un paradigma o un modelo de hombre bueno o realizado» (2016, p. 56).

En lo que atañe al rechazo postmoderno de la tradición, Poole reitera acertadamente la necesidad de la naturaleza humana de la tradición, por mucho que los actuales tiempos postmodernos quieran trascenderla. La tradición hace que la experiencia sobrepase los estrechos límites del aquí y ahora para servir a las futuras generaciones. «El pasado, por la tradición, se hace normativo, pero no por ser pasado, sino porque ha sido 
probado, validado, por la experiencia (ibídem, p. 32). Por eso existe la tradición: formas de vida probadas y purificadas por la experiencia de nuestros predecesores. $\mathrm{Y}$ el valor más preciado de una tradición es la moral. Toda verdadera tradición es portadora de moral (ídem). Y, según el académico Kreeft, «aquellas sociedades que han sido las más tradicionales, han sido también las mejores moralmente y las más prósperas» (1999, p. 59). Poole destaca la generalización actual del uso del término valores para referirse a la moral, en lugar de los términos clásicos de «virtudes, leyes o bienes» (2016, p. 18). En lo que atañe a la moral y su relación con la religión, Poole destaca el hecho de que la historia demuestra que, «en los cimientos de cualquier sistema moral que ha tenido un mínimo de consistencia y duración en la historia se encuentran las grandes religiones. La religión es el soporte más firme de la moralidad. La moralidad siempre ha necesitado la religión» (2016, p. 37). Por su parte, Kreeft añade que «si destruimos la religión, destruimos la moral, y si destruimos la moral, destruimos la sociedad» (1999, p. 162). En lo que respecta a la existencia objetiva de la verdad, elemento negado por el relativismo, la tradición filosófica siempre ha entendido que «el amor a la verdad y la fe en el poder de la inteligencia, son la primera condición de la indagación filosófica» (Hegel, 1818, citado por Poole, 2016, p. 55).

Estos primeros años del siglo XXI constituyen un período de notable crisis y cambio por la irrupción de los fenómenos de la globalización y el postmodernismo. El impacto de estos fenómenos en la epistemología de nuestra ciencia comparada se ha revelado con una virulencia especial, dada la ya mencionada vulnerabilidad epistemológica en ámbitos nucleares ya citados como la definición y acotamiento de su objeto de estudio. Desde la reflexión académica personal En relación con el statu quo epistemológico de la Educación Comparada, considero que el trabajo científico de nuestra disciplina ha estado durante su desarrollo en los siglos XIX y XX (y también en el actual siglo XXI), fundamental y exclusivamente centrada en los procesos educativos (ie. el funcionamiento de los sistemas educativos; la entidad de las políticas y las reformas educativas, etc.). Esos procesos son cambiantes por naturaleza y por evolución histórica y, por ello, una ciencia cimentada de forma exclusiva en los mismos, no acaba de encontrar su arraigo doctrinal (más allá de que una disciplina siempre tiene que estar abierta a la evolución con las nuevas etapas históricas). La Educación Comparada ha descuidado a lo largo de su historia su atención gnoseológica a los actores del proceso educativo (ie. muy especialmente la concepción de persona humana sujeto de la acción educativa comparativa), y a la finalidad de dicho proceso (ie. notablemente, la idea de la sociedad mundial pretendida y hacia la que se tiende). La concepción de la persona humana no varía ni está sujeta a las crisis de los tiempos, y la finalidad última y más esencial de la sociedad mundial (en términos de paz mundial y felicidad, al estilo de un Proyecto de una ética mundial, como la propuesta por el teólogo Hans Küng) tampoco. Sólo desde una Educación Comparada de cuño también filosófico y teológico (y no meramente histórico, sociológico y político) tendrán respuesta inquietudes como las mostradas por Cowen relativas a los criterios que deben presidir la emisión de juicios -hasta ahora «mayormente ausentes en los escritos de los comparatistas»- (Cowen, 2009, p. 962).

Decíamos en líneas anteriores que la moralidad ya no está fundida en una religión revelada y que, desde la filosofía de Ockam y el empirismo, la moral se entiende como sentimiento en lugar de conocimiento. El Dr. Sayés es el autor de una extraordinaria y muy clarificadora obra de análisis del relativismo contemporáneo en la sociedad española y mundial. A su entender, es en los postulados de la Ilustración donde se ubican los 
principios que enmarcan la ideología laicista de nuestra época, pues en ellos se suprimen la metafísica y la fe como ámbitos del conocimiento humano y, con ello, la fundamentación de la religión o la moral. Sin esa fundamentación, no es posible abordar la emisión de juicios de valor sobre criterios certeros que echa en falta el catedrático británico Cowen en los trabajos comparativos.

Es mi convicción personal y académica que el logro de una cimentación epistemológica sólida de la disciplina comparativa pasa por la articulación y vertebración de una firme y cristiana idea de persona y sociedad (actores), y de los fines culturales y sociales europeos y mundiales (finalidad), en cuya articulación se requiere el concurso de las directrices y presupuestos ontológicos procedentes de las ciencias teleológicas: la Filosofía y, muy especialmente, la Teología. En estos momentos de relativismo y de negación de las metanarrativas universales, solo determinados presupuestos de la ciencia teológica pueden establecerse como componentes de una epistemología postrelativista y superar la tan mentada posverdad como aseveración que no se basa en hechos objetivos, sino en las emociones, creencias o deseos.

En este sentido podemos con toda certeza afirmar que, en el actual mundo de la segunda década del siglo XXI, afrontamos una gran contradicción desde el punto de vista axiológico y espiritual. Por un lado, la sociedad mundial revela un grado innegable de secularización como nunca antes en la historia. Como afirma el historiador Sotelo, «el concepto de Postmodernidad implica una ruptura semejante a la que ocurrió con la aparición del Cristianismo, y supone que este habría llegado a su fin. La identidad del Cristianismo con la Modernidad pone de relieve que, en rigor, la Postmodernidad implicaría un mundo que hubiera roto hasta las últimas amarras con el Cristianismo» (Sotelo, 2003, p. 58). Sotelo esboza que Jaspers en 1932 caracterizaba la situación espiritual de nuestro tiempo con dos rasgos distintivos: el predominio del ateísmo y la dominación de la técnica, dos fenómenos que influyen de manera decisiva en los más variados aspectos de la vida material y espiritual. Al parecer de Sotelo, la noción de Postmodernidad habrá que involucrarla a la crisis radical de los valores cristianos, tanto en sus formas conscientemente religiosas, como aquellas ya secularizadas. Nietzsche, al llevar a sus últimas consecuencias la crítica radica de lo cristiano, es el filósofo que anuncia la Postmodernidad (ídem). «Pensar la Postmodernidad, en último término, consisten en hacerse cargo de la muerte de Dios con todas sus implicaciones. La Postmodernidad, en este sentido, no sería otra cosa que una interpretación del mundo consecuentemente atea» (ibídem, p. 59).

Por otra parte, no obstante, podemos afirmar que este aparente consenso y triunfo del secularismo reinante dista, en el fondo, de atestiguar todo el cuadro de la situación espiritual de nuestro tiempo. Reputados comparatistas como el profesor Cowen, en su emblemático International Handbook of Comparative Education, IHCE, al hablar de la construcción de la identidad en tiempos moderno-tardíos, alude al hecho de que «en la alteración de la naturaleza de los entornos educativos en la modernidad tardía, la cuestión de las culturas educativas y la identidad pedagógica tiende a desvincularse de nociones como ciudadanía, y a devenir más y más poderosamente vinculada a la economía o la religión» (Cowen \& Kazamias, 2009, p. 6. La cursiva es mía). De hecho, los comparatistas Cowen y Kazamías, en su IHCE dedican una sección entera de esta obra a la temática religiosa. De igual modo, la conferencia presidencial del Dr. David P. Baker en la norteamericana Comparative and International Education Society, CIES, en el año 2013, reivindicó más investigación educativa comparada e internacional a la relación entre educación y religión: «Quizá un fenómeno más descuidado y prometedor de investigación para 
la Educación Comparada e Internacional es la entidad de la religión y la espiritualidad en la sociedad escolarizada» (Baker, 2014, p. 16). Baker afirma que la religión ha sido imposible de erradicar a lo largo del mundo; que, en la nación americana, a finales del siglo XVIII solo el 17 \% de la población total practicaba la religión, pero a finales del siglo XX la filiación eclesiástica ha crecido al $60 \%$, y el $95 \%$ de los americanos afirman creer en un dios. La religión prospera a lo largo del mundo (ídem). Sigue Baker afirmando que la espiritualidad no deviene marginal o irracional para muchos individuos. La revolución educativa, entendida como progresiva democratización de todos los niveles de la educación a la población, establece las bases para un pluralismo religioso extenso, y conduce a una mayor adhesión religiosa (ibídem, p. 17). La religión y la espiritualidad, prosigue Baker, no declinan en la sociedad escolarizada, y pueden incluso prosperar. La sociedad escolarizada y su espiritualidad educadas crecerán en el futuro. Las siguientes palabras tienen muchas implicaciones para los comparatistas: «Esto revela un gran potencial para la investigación de la Educación Comparada e Internacional, que ha estado virtualmente muda en la materia. Hasta la fecha, toda la investigación ha sido realizada por científicos sociales interesados en la religión, no particularmente en educación. Esto demanda un estudio comparado más sistemático. Y es un tema futuro central para la investigación en Educación Comparada e Internacional» (ibídem, p. 18). Para hacer frente al relativismo imperante en nuestro mundo actual y, en concreto, desde la disciplina de la Educación Comparada, necesitamos incorporar a nuestro saber algunas de las directrices y presupuestos ontológicos procedentes del ámbito de la Teología, ciencia teleológica de la educación que tradicionalmente ha sido relegada al olvido. Como afirma García Garrido, «el reconocimiento de la Teología de la Educación como ciencia está supeditado a una previa toma de posición de la Filosofía de la Educación. Sólo una filosofía que opte a favor del principio de transcendencia permitirá el posterior establecimiento, como saber distinto, de una Teología. Por el contrario, la opción por una concepción inmanente de la realidad conlleva, como lógica consecuencia, la negación de toda realidad exterior al mundo físico y humano y de su posibilidad de estudio científico» (1996, p. 214).

Existe una Teología de la Educación desde el momento en que un nutrido grupo de estudiosos se consagra a ella con suficiente base científica. Para estos estudiosos, la opción de transcendencia supone admitir que el fin de la educación no es exclusivamente de alcance terrenal. Como afirma García Garrido, «si para el hombre es importante su destino eterno, esto significa que la educación no puede desentenderse de este importante tema. Es entonces cuando entran en juego las creencias religiosas y, de modo especial, la admisión de la Revelación divina como fuente de conocimiento. En este supuesto, la Teología de la Educación analizaría el mensaje revelado con el fin de encontrar en él los principios teológicos por los cuales debería regirse el proceso educativo. Y, como es lógico, la Teología de la Educación sería subsidiaria de las concretas creencias religiosas que se profesasen. Existen, teóricamente hablando, tantas Teologías de la Educación como religiones (García Garrido, 1996, p. 215).

La Educación Comparada como ciencia debe apuntar, en su doble finalidad teóricopráctica, y en su condición de ciencia analítico-sintética, a dar cumplida respuesta a esta dimensión espiritual, y a apuntar a elevados horizontes espirituales y axiológicos para la sociedad mundial actual. Este y no otro es el mejor legado que esta disciplina puede dejar a los futuros ciudadanos mundiales. También esta finalidad axiológica conlleva y supone una cimentación sólida de la epistemología de la disciplina comparativa, pues dichos horizontes teleológicos se revelan de estabilidad permanente, aun cuando la sociedad humana evolucione y cambie. Estas reflexiones nos conducen al siguiente $-\mathrm{y}$ últimoepígrafe de este estudio. 


\section{Teología y Educación Comparada}

Al comienzo del artículo hemos analizado la situación fragmentada y estéril de la epistemología comparada en estos años del siglo XXI. Es mi hipótesis que, en la revitalización de nuestro campo de estudio, la Educación Comparada debe asumir su rol central En relación con la definición de la naturaleza y atributos de la persona humana íntegramente considerada objeto de la educación en su trabajo comparado, y también en lo que atañe a la conformación de las finalidades históricas, sociales y espirituales de las culturas mundiales a que dichas personas pertenecen y cuyo logro se ansía. El análisis, a modo de ejemplo, de las bondades de una pedagogía formal frente a una progresista, o de un modelo de escuela diversificada frente a una comprensiva, o de una educación diferenciada frente a una mixta, o de la ubicación de los diversos países en el baremo de PISA, etc., no tienen ningún sentido ni objeto si no atiende a la entidad e identidad de la persona humana que se pretende formar, y a la sociedad y cultura deseada y en la que dicha persona se va a integrar y va a modelar. Por lo tanto, procede operar la reflexión de la entidad y atributos de la persona humana, íntegra y completamente considerada, y de las finalidades legítimas de las sociedades y culturas a las que pertenece. Podríamos establecer como objeto de estudio de la Educación Comparada en los actuales tiempos postmodernos, el siguiente: «El logro, a través de la educación y los sistemas, políticas y reformas educativas mundiales, de personas y sociedades libres, comprometidas y desarrolladas en todas sus dimensiones, y de culturas y civilizaciones solidarias e inclusivas, a través del método comparado y el consejo de las ciencias teleológicas del saber».

En esta labor, la Educación Comparada debe atender a las directrices marcadas por la Teología actual. Una de las obras, anteriormente citada, que arrojan más luz a este respecto es la de Sayés, Teología y relativismo. Análisis de una crisis de fe. Afirma Sayés en su obra que «hoy día la Teología está enferma, y en consecuencia, no se puede transmitir la fe, porque no se fundamentan las certezas que se deben transmitir» (Sayés, 2012, p. IX). Sayés muestra el inicio de la teología de la secularización de forma cronológicamente coincidente con el término del Concilio Vaticano II, y causa de que se interpretara el Concilio en ruptura con la tradición. Las heridas de la teología de la secularización (cuya crisis de fe llegó mucho antes a la teología y a los seminarios que a la misma sociedad), con autores como Bonhoeffer, Robinson, Cox, Altizer, Hamilton, Vahanian, Van Bureu, siguen abiertas en la teología actual. En los años del posconcilio, expone Sayés, se nos presentaba esta teología de la secularización como la auténtica interpretación de Gaudium et spes -única constitución pastoral del Concilio Vaticano II- cuando en realidad dicha teología no tenía nada que ver con el Concilio (ibídem, p. X). Sacerdotes como el Cardenal Seper hacen constar la «abundancia actual de la literatura sobre el ecumenismo, siendo que, en realidad, la crisis doctrinal católica es, al presente, un terrible obstáculo para el ecumenismo» (ídem). Es en los postulados de la Ilustración, como hemos afirmado, donde se ubican los principios que enmarcan la ideología laicista de nuestra época. Al parecer de Sayés, «Se pretende reducir las doctrinas de la revelación a verdades naturalmente evidentes y racionalmente demostrables, e interpretar la fe cristiana como pura religión racional, privándole así de su índole sobrenatural y de su carácter de misterio: la revelación y el milagro, la encarnación y la redención, la acción de los sacramentos para obrar la gracia, etc., quedan suprimidos de un plumazo» (ibídem, p. 30). La teología de la secularización, nacida de una crisis de fe y de la incapacidad de vivir una oración gratificante (ibídem, p. 6) todavía perdura entre nosotros, y lo 
hace enlazando con el movimiento laicista que reina en nuestra época. La teología de la secularización ha querido suprimir a Dios de la sociedad y del mundo para reducirlo a un sentimiento interior de la conciencia. Como afirma Sayés, «con la influencia de estos pensamientos, hoy día se quejan muchos de que las homilías no dicen nada. Perdidas las certezas, ya no se puede iluminar ni fundamentar la fe» (ibídem, p. 31). «Hoy no se transmite la fe, porque en realidad está enferma» (ibídem, p. 32).

A pesar de que expone Sayés que, según Ratzinger, el pluralismo teológico se sustenta con frecuencia en un puro subjetivismo; que un teólogo que intente ser fiel a la doctrina queda relegado (ibídem, p. 35), y que es difícil que un teólogo sea prestigioso si no tiene algo o mucho de disidente respecto de la «la doctrina» oficial de la Iglesia (a cuya adhesión es catalogado como adherente a una teología caduca, superada, meramente repetitiva, ininteligible para el hombre de hoy, creyente o incrédulo) (ídem), este autor lanza un mensaje de esperanza, optimismo y firmeza en el cuerpo de doctrina tan amplio y tan perfecto, se trate de temas dogmáticos, bíblicos, morales, etc.». «El Catecismo es una auténtica catedral de doctrina que durará mucho tiempo como ley de orientación» (ibídem, p. 34). Al decir de Sayés: «Gracias a Dios, a pesar de la crisis actual, la Iglesia sabe lo que cree» (ibídem, p. 36). De este vasto cuerpo doctrinal, cabe extraer no solo criterios éticos firmes postrelativistas para valorar comparativamente las pedagogías mundiales -elemento que reclama el académico británico Cowen- sino también algunas de las finalidades últimas para las sociedades y culturas mundiales (ie. atención a la dimensión transcendente; carácter comunitario de la vocación humana, virtudes, deseo de felicidad y vocación a la bienaventuranza, acción libre y responsable, justicia social, moralidad de los actos humanos, etc.). Es generalmente admitido que a las humanidades y las ciencias sociales, muy particularmente la Educación Comparada, compete, más que a otras disciplinas, el diseño del modelo de sociedad y de hombre para el siglo que ha comenzado (García Ruiz, 2011, p. 526). Entre dichas ciencias, es la ciencia del espíritu de la Teología la que goza del atributo de vigía humano y social por excelencia. Por su parte, el concepto de persona humana cabe también extraerlo, por la riqueza y compleción que presenta, de la tradición cristiana. El concepto de persona, tan usado por las ciencias del espíritu, tiene una profunda raíz en la teología cristiana occidental, Esta raíz cristiana, reflexionada, madurada y articulada desde la época patrística, medieval, renacentista y contemporánea, ha configurado no solo el concepto sino, además, una reflexión en torno al valor y dignidad del hombre. En el pensamiento de los grandes teólogos de los siglos XX y XXI, la persona humana tiene un gran significado en su dimensión teologal-relacional (Buriticá, 2014, pp. 467-468); como persona abierta y en relación con lo trascendente. La revelación cristiana confiere al hombre la capacidad de encuentro con el «otro», la alteridad, como condición necesaria para la radical comprensión de sí mismo. La raíz cristiana del término persona plantea que es desde la relación donde se encuentra la identidad del ser humano. De un modo fundamental, la relación que define y orienta la verdadera identidad es la relación con el Ser Trascendente, con quien el hombre establece un diálogo definitivo y que lo abre a sus múltiples posibilidades, para responder de manera adecuada a los desafíos propios de su condición. Esta relación le da a la persona una medida más allá de sus propios límites, pero con un sentido solidario hacia los demás; reconoce que, en todos los seres humanos, dicha relación con lo trascendente es posible y realizable y que, a su vez, ella abre, de manera particularísima, a una relación con el otro (persona, igual, hermano) desde la entrega y la solidaridad, y con lo otro (mundo, criatura, objeto) desde la responsabilidad (ibídem, pp. 490-491). Pedro Abelló 
alude a las trece notas del concepto de persona cuya integración y consideración en toda actividad educativa, y análisis y cotejo comparado, deberían contemplarse: 1) naturaleza espiritual, 2) libertad, 3) centralidad, 4) unicidad/inaprensibilidad, 5) singularidad, 6) condición de sujeto y soporte del ser, 7) dinamismo/autosuperación, 8) virtualidad/ potencialidad, 9) sinergismo, 10) universalidad, 11) relacionalidad, 12) autonomía, 13) naturaleza sacrificial.

\section{Conclusiones}

Los académicos comparatistas nos enfrentamos, en esta segunda década del siglo XXI, a la construcción epistemológica de la ciencia comparativa de la educación desde el contexto cultural y filosófico de la postmodernidad y sus planteamientos de crisis del universalismo, complejidad, impredecibilidad, y pérdida de las legitimaciones tradicionales. La resolución de la crisis epistemológica de nuestra disciplina de la Educación Comparada, y de sus vulnerabilidades gnoseológicas (muy particularmente el disenso en la consideración de su objeto de estudio), así como la sanción de una fase científica postrelativista, requiere del trabajo interdisciplinar con las ciencias teleológicas que proporcionen unos elementos científicos a nivel de actores y finalidades del proceso educativo comparado, que cimienten y orienten definitiva y sólidamente la disciplina y la capaciten para proseguir tanto su desarrollo académico teórico, como sus recomendaciones y propuestas prácticas a la clase política nacional y mundial, de forma consolidada y firme.

\section{Referencias bibliográficas}

Abelló, P. Sobre el concepto de persona. En http://es.catholic.net/op/articulos/54939/ cat/403/sobre-el-concepto-de-persona.html.

Anderson, P. (2000). Los orígenes de la posmodernidad. Madrid: Akal.

Aullón de Haro, P. (2018). La cuestión universitaria y las ciencias humanas en tiempos de globalización. Metodologías Humanísticas en la Era Digital, vol. 1, 15-43.

Baker, D. P. (2014). Minds, Politics and Gods in the Schooled Society: Consequences of the Education Revolution. Comparative Education Review, 58(1), 6-23.

Buriticá Zuluaga, D. A. (2014). El concepto de persona humana en la tradición cristiana y su progresión hasta el personalismo. Cuestiones Teológicas, vol. 41, $\mathrm{n}^{0}$ 96, pp. 467-493.

Carney, S. (2010). Reading the Global: Comparative Education at the End of an Era. En M. A. Larsen (Ed.), New Thinking in Comparative Education (125-142). Rotterdam: Sense Publishers.

CER Editorial Team (2017). On Methodology in Comparative and International Education. Comparative Education Review, vol. 61, no 4, 669-674.

Cowen, R. (2009). Editorial Introduction: New Thinking. En R. Cowen and A. Kazamias (Eds.), International Handbook of Comparative Education (961-964). Dordrecht: Springer. 
Cowen, R. and Kazamias, A. (2009). Joint Editorial Introduction. En R. Cowen and A. Kazamias (Eds.), International Handbook of Comparative Education (3-6). Dordrecht: Springer.

Discurso del Papa Juan Pablo II en el Acto Europeo en Santiago de Compostela, martes 9 de noviembre de 1982.

García Garrido, J. L. (1996). Fundamentos de la Educación Comparada. Madrid: Dykinson.

García Ruiz, M. J. (2011). Impacto de la Globalización en la universidad europea del siglo XXI. Revista de Educación, 356, pp. 509-529.

García Ruiz, M. J. (2012). Impacto de la Globalización y el Postmodernismo en la epistemología de la Educación Comparada. Revista Española de educación Comparada, vol. 20, 41-80.

Habermas, J. (1988). Modernidad versus Postmodernidad. En J. Picó (Ed.), Modernidad y Postmodernidad. Madrid: Alianza Editorial.

Küng, H. (2006). Proyecto de una Ética Mundial. Madrid: Editorial Trotta. $7^{\mathrm{a}}$ ed.

Kunitz, S. J. (Ed.) (1955). Twentieth Century Authors - First Supplement. Nueva York.

Manzón, M. (2014). Cambio de forma de la Educación Comparada: hacia una historia comparada de la disciplina. En M. Larsen (Ed.), Pensamiento Innovador en Educación Comparada. Homenaje a Robert Cowen (127-151). Madrid: UNED.

Olson, C. (1966). Projective Verse. En R. Creeley, (Ed), Selected Writings. Nueva York.

Poole Derqui, D. (2016). Relativismo y Tolerancia. Madrid: Digital Reasons.

Rappleye, J. (2014). Brújulas, mapas y espejos: reubicando la epistemología de la transferencia. Reorientando el cosmos comparativo. En M. Larsen (Ed.), Pensamiento Innovador en Educación Comparada. Homenaje a Robert Cowen (93-123). Madrid: UNED.

Rust, V. D. (1991). Postmodernism and its Comparative Education Implications. Comparative Education Review, 35(4), 610-626.

Sayés, J. A. (2012). Teología y relativismo. Análisis de una crisis de fe. Madrid: BAC.

Schriewer, J. (2000) (Ed). Discourse Formation in Comparative Education. Frankfurt am Main: Peter Lang.

Sotelo Martínez, I. (2003). La invención de Europa: la realidad histórico-cultural de Europa. En AA.VV., La formación de europeos. Actas del Simposio de Barcelona. Madrid: Academia Europea de Ciencias y Artes. 